\title{
Cue selection in paired-associate learning: Meaningfulness and position
}

EUGENE A. LOVELACE

UNIVERSITY OF VIRGINIA

Twenty-four common English words were learned as responses to compound stimuli, each of which was composed of two trigrams connected by a hyphen. One trigram of each stimulus was high $m$, one low $m$; half of the stimuli had the high $m$ item in the left-hand position, half in the right. In a transfer task Ss responded to one trigram of each stimulus. The data obtained suggest that both $\underline{m}$ and position of the components determined cue selection.

If the $S$ in a paired-associate (PA) learning task is presented compound stimuli he may respond to a selected component of each stimulus. Several studies suggest that more meaningful elements are favored (Underwood, Ham, \& Ekstrand, 1962; Cohen \& Musgrave, 1964; Jenkins \& Bailey, 1964). Cohen \& Musgrave (1964) reported that for stimuli composed of two low meaningful CVC trigrams the trigram occurring in the left position became associated with the response better than the trigram in the right position. Position was not, however, a significant factor when the stimuli were composed of two three-letter words. James \& Greeno (1967, Experiment II) employed compound stimuli where each stimulus was composed of a threeletter word and a trigram of low meaningfulness (m). They failed to obtain a significant effect of position on cue selection when the two types of stimulus components (words and trigrams) occurred equally often in each position. The present study confirms the relevance of $\underline{m}$ and position for selection effects with compound stimuli.

Method

Meaningfulness and trigram position were manipulated as within-s variables. The design involved the learning of 24 pairs composed of compound trigram stimuli and common English word responses, and the measurement of performance to single elements of the compound stimuli in a transfer task. Each stimulus item for PA learning was composed of two CVC trigrams connected by a hyphen. In each case one trigram was high $\underline{m}$ and the other low $\underline{m}$. Half the stimuli for acquisition had the high $\underline{m}$ member on the left $(H-L)$, half had the low $m$ item on the left $(\mathrm{L}-\mathrm{H})$. Acquisition trials were given by the study-test method. The transfer task continued the PA task, but only one CVC of each stimulus appeared on the test trials (the hyphen was present to provide position information). For half the $\mathrm{H}-\mathrm{L}$ stimuli the high $\underline{\mathrm{m}}$ item was presented on the transfer trials $(\mathrm{H}-)$; the remaining $\mathrm{H}-\mathrm{L}$ stimuli had the low $\underline{m}$ CVC presented $(-L)$. Similariy, for the
L-H stimuli half were presented as L- stimuli on the test portion of transfer trials and half as $-\mathrm{H}$ stimuli. Thus, on the transfer trials, four experimental conditions resulting from the factorial combination of high and low $\underline{m}$ components with left and right positions were represented in a single 24-pair list, six pairs in each condition.

The 18 Ss were run in a single group session. Stimulus materials were presented by a slide projector at a 4 sec rate with a 4 sec intertrial interval. On study trials the compound stimulus appeared above the response word. On test trials during acquisition each compound stimulus appeared for $4 \mathrm{sec}$ during which time Ss wrote their responses in booklets. After 10 acquisition trials the Ss were instructed that pairings would remain the same, but that on test trials they would see only one-half of each stimulus. Study trials remained the same. Four transfer trials were given, but the study portion of the first of these trials was deleted so that Ss were tested immediately after receiving instructions regarding the change in procedure.

The response terms were A or AA in Thorndike \& Lorge (1944). The low $\underline{m}$ CVCs had a range of association values (AVs; Archer, 1960) from 6 to 26 (X $=17.8$ ); the high $\mathrm{m}$ set had an $\mathrm{AV}$ range from 74 to 99 $(X=89.3)$. Within each level of $\underline{m}$ no initial consonant was used more than once, and no sequence of two letters was repeated. In the set of $48 \mathrm{CVCs}$ there were no two CVCs with the same consonants in the same positions. The pairings of high and low $\mathrm{m}$ items to form compound stimuli were random with the restriction that the two CVCs have no letters in common.

The Ss were 18 male undergraduate students at the University of Virginia who were naive with respect to PA procedures and the materials used.

\section{Results and Discussion}

The mean number of correct responses made on each trial to the six pairs in each of the four transfer conditions is shown in Fig. 1. It can be seen that by the end of 10 PA trials all Ss were getting nearly all responses correct (every $S$ had at least one perfect trial). Further, it is apparent that the four sets of pairs do not differ systematically in difficulty since the four acquisition curves overlap. Performance on the first trial of the transfer task shows differential performance decrements for the four transfer conditions. Analysis of correct responses on the first transfer trial indicated significant effects for both $\underline{m}(F=31.96$, 


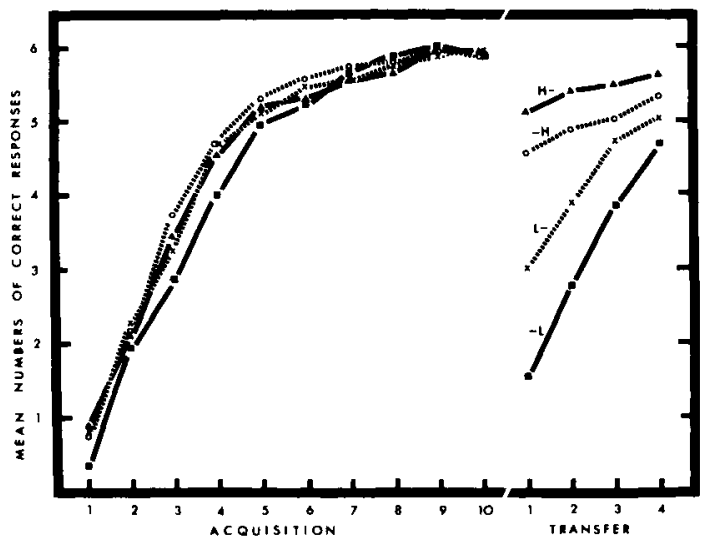

Fig. 1. Mean numbers of correct responses to the four sets of six pairs as a function of trials during acquisition, and in the transfer task where each set represents one of the four different $m$-position combinations of stimulus components.

df $=1 / 17, p<.001)$ and trigram position $(F=5.47$, df $=1 / 17, p<.05)$. The interaction did not approach statistical significance (p>.10).

To what extent are these effects representative of relative use of stimulus components by all Ss? Performance on the first transfer trial suggests that the results reported above reflect an averaging of several strategies. For some Ss little selection seemed to occur, e.g., three Ss showed differences no greater than one response among the four conditions. Some Ss clearly selected on the basis of $\mathrm{m}$, e.g., one $\mathrm{S}$ responded correctly to 11 of 12 high $\mathrm{m}$ components, but failed to respond correctly to any low $\underline{m}$ items. Other Ss selected primarily on the basis of position, e.g., one S responded correctly to all 12 elements from the left position, but had only one correct response to elements from the right position. The reports of many Ss indicated that these strategies were consciously employed during PA acquisition. For 11 of the 18 Ss there was a greater difference in their performance on high and low $m$ items than their performance to left- and right-position items.
For four Ss the reverse was true, the difference being greater for the position variable than for $\underline{m}$. The remaining three Ss showed no difference in the magnitude of these two differences.

The present findings are consistent with Cohen and Musgrave's report that stimulus cue selection is based on $\underline{m}$ and position of the components. However, the fact that $\underline{m}$ yields a greater effect than position seems to derive from a larger number of individuals selecting on such a basis rather than $\underline{m}$ yielding a larger selection effect in all Ss.

Although the hyphenated stimuli of the present study might be expected to possess greater psychological unity than the two discrete, physically-separated stimulus components of the Cohen and Musgrave study, it is apparent that great amounts of selection did occur. The interaction of $m$ and element position which Cohen and Musgrave reported was not obtained. In the present study position seemed an effective determiner of selection for high $\underline{m}$ as well as low $m$ items. There are, of course, a number of procedural differences between the two studies which may account for this difference: (a) whether the high $\underline{m}$ items were real English words; (b) position of the stimuli with respect to the response on study trials (beside vs above); (c) class of response materials (single letters vs English words); (d) mode of responding (spoken vs written); (e) hyphenation vs physical separation of the stimulus components.

\section{References}

ARCHER, E. J. A re-evaluation of the meaningfulness of all possible CVC trigrams. Psychol Monogr., 1960, 74, (10, Whole No. 497). COHEN, J. C., \& MUSGRAVE, B. S. Effect of meaningfulness on cue selection in verbal paired-associate learning. J. exp. Psychol., 1964, $68,284-291$.

JAMES, C. T., \& GREENO, J. G. Stimulus selection at different stages of paired-associate learning. J. exp. Psychol, 1967, 74, 75-83.

JENKINS, J. J., \& BAILEY, V. B. Cue selection and mediated transfer in paired-associate learning. $J$. exp. Psychol, 1964, 67, 101-102.

THORNDIKE, E. L., \& LORGE, I. The teacher's word book of 30,000 words. New York: Teacher's College, Columbia University Press, 1944. UNDERWOOD, B. J., HAM, M., \& EKSTRAND, B. Cue selection in paired-associate learning. J. exp. Psychol, 1962, 64, 405-409. 